\title{
Efektifitas Edukasi Pada Caregiver Tentang Pengetahuan Kejadian Pengabaian Lansia
}

\author{
Lola Felnanda Amri ${ }^{1}$, Renidayati ${ }^{2}$ \\ Prodi D III Keperawatan Padang, Poltekkes Kemenkes Padang \\ Jalan Raya Siteba, Surau Gadang Kecamatan Nanggalo Padang, 25146 \\ Email: felnandalola@yahoo.com
}

\begin{abstract}
Abstrak
Pengetahuan erat kaitannya dengan tingkat pendidikan serta prilaku seseorang. Perilaku yang didasari oleh pengetahuan akan lebih langgeng dari pada perilaku yang tidak didasari oleh pengetahuan. Dalam merawat seorang lanjut usia, dibutuhkan Caregiver yang memiliki pengetahuan khusus agar dapat membantu aktifitas lansia dengan tepat sehingga lansia bisa menghabiskan sisa hidupnya dengan aman dan nyaman. Tujuan penelitian ini adalah Mengetahui efektifitas edukasi pada pengasuh lansia (Caregiver)tentang kejadian pengabaian lansia. Desain penelitian adalah kuasi eksperimen dengan rancangan one group pretest posttest.Penelitian dilaksanakan di PSTW X Sumatera Barat.Populasi sebanyak 24 orang, jumlah sampel sebanyak 23 orang. Hasil penelitian Caregiver terbanyak berada di usia lansia awal yaitu sebanyak 8 orang (34,8\%), tingkat pengetahuan sebelum edukasi kategori baik yaitu sebanyak 20 orang (87,0\%), sesudah edukasi kategori baik yaitu sebanyak 18 orang (78,3\%). Tidak ada perbedaan yang signifikan antara pengetahuan Caregiver sebelum dan sesudah diberikan edukasi dengan $P$ Value 0,310.Disimpulkan sangat dibutuhkannya peningkatan pengetahuan Caregiver terutama tentang kesejahteraan lansia. Disarankan pada dinas terkait untuk memenuhi kebutuhan panti akan perawat professional, memberikan pelatihan pada seluruh Caregiver tentang kesejahteraan lansia, serta memfasilitasi pegawai untuk melanjutkan pendidikan.
\end{abstract}

Kata kunci : Caregiver, Edukasi, Pengetahuan, Panti sosial tresna werdha

\section{Effectiveness of Education on Knowledge About The Event Negligence Caregiver Elderly}

\begin{abstract}
Of knowledge closely related to levels of education as well as the behavior of a person, the behavior has based on knowledge will be more lasting than the behaviors that have not based on knowledge. In caring for an elderly, needed a Caregiver has specialized knowledge to help the elderly activities appropriately so that the elderly can spend the rest of their life with safe and comfortable. The purpose of this research is to know the effectiveness of education on caregiver elderly waiver about events in PSTW Sabai Nan Aluih SicincinKab. West Sumatra Padang Pariaman.Design research was quasi-experimental with the pretest-posttest design of one group. This research was carried out in PSTW Sabai Nan AluihSicincinKab Padang Pariaman.The population of as many as 24 people, the number of samples according to criteria of inclusion as many as 23 people. Results of the study is in the age of most Caregiver elderly initial i.e. as many as 8 people (34.8\%), the level of knowledge before the educational category of good that is as much as 20 people (87.0\%), having both categories namely education as much as 18 people (78.3\%). There is no difference significant between knowledge education provided before the caregiver with a $P$ Value 0.310. Summed up very high increase in Caregiver knowledge primarily about the welfare of the elderly. It is recommended in the associated service to meet the needs of the professional nurse, will provide training on the whole welfare of elderly Caregivers, as well as facilitate employees to continue their education.
\end{abstract}

Keywords: Caregiver, Education,Knowledge, Panti Sosial Tresna Werdha 


\section{PENDAHULUAN}

Usia harapan hidup penduduk meningkat, akan menyebabkan jumlah penduduk lanjut usia bertambah dari tahun ke tahun. Meningkatnya usia harapan hidup penduduk merupakan salah satu dampak dari peningkatan kualitas kesehatan serta keberhasilan pembangunan dan sekaligus meningkatkan populasi beresiko (lanjut usia) (Amri, 2015). Individu lanjut usia di masukkan kedalam kelompok resiko tinggi, dikarenakan adanya penurunan serta perubahan kondisi/fungsi tubuh dari lansia tersebut. Sesuai dengan penuturan Maurier dan Smith (Amri, 2015), yang menjelaskan bahwa :penurunan kondisi kesehatan individu/kelompok dipengaruhi oleh banyak faktor sehingga individu/kelompok tersebut menjadi bagian dari kelompok yang beresiko.

Berdasarkan kondisi karakteristik resiko yang dialami oleh lansia ini, maka akan meningkatkan ketergantungan lansia pada keluarga dan Caregiver. Peningkatan ketergantungan lansia akan berdampak terhadap perlakuan pada lansia itu sendiri sehingga lansia beresiko untuk tidak terpenuhi semua kebutuhannya, dengan demikian secara tidak langsung keluarga dan masyarakat mengalami kegagalan dalam memberikan pelayanan kepada lansia atau dengan kata lain pemahaman yang tidak tepat terhadap lansia menyebabkan seringnya lansia diabaikan (Potter.A.P \& Perry.G. A., 2009).

Pengabaian pada lansia merupakan bagian dari kejadian salah perlakuan. Alon (2006 dalam (Winterstein, 2012)), menyatakan bahwa pengabaian pada lansia merupakan salah satu bagian salah perlakuan yang dilakukan oleh anggota keluarga dan Caregiver. Pengabaian pada lansia bisa diartikan sebagai kegagalan Caregiver atau anggota keluarga untuk memenuhi kebutuhan dasar lansia, baik itu kebutuhan secara fisik maupun kebutuhan kesehatan secara mental (Stanhope, M \& Lancester, 2004 dalam Amri, 2013).
Hasil penelitian Fullmer et al (2005 dalam (Amri, 2013)), menyatakan bahwa pengabaian yang dilakukan oleh pasangan sebanyak $11,5 \%$, anak laki-laki sebanyak $3.8 \%$, menantu perempuan sebanyak $3,8 \%$, anggota keluarga lainnya 3,8\%, dan lainnya $4 \%$, serta kejadian pengabaian paling banyak dilakukan oleh Caregiver yang dibayar (formal) yaitu sebanyak $73,1 \%$.Kejadian pengabaian ini juga bisa disebabkan oleh beban mental Caregiver, status fungsional Caregiver, depresi /gangguan suasana hati Caregiver, status kesehatan Caregiver, suport sosial, trauma yang pernah dialami Caregiver di waktu kecil, karakter/kepribadian Caregiver.

Jenis dari pengabaian ini adalah pengabaian psikologis (emosional), dan fisik yang dilakukan secara sengaja maupun tidak disengaja (Winterstein, 2012). Pengabaian ini juga bisa disebabkan oleh beberapa faktor yaitu faktor yang bersumber dari diri lansia itu sendiri/internal dan faktor yang berasal dari Caregiver/eksternal (Fulmer. T. Et, Al, 2005 dalam (Amri, 2013).

Kejadian pengabaian lansia ini disebabkan oleh status kognitif dari Caregiver, demografi Caregiver (usia, jenis kelamin, ras, agama, latar belakang pendidikan, status perkawinan, status pekerjaan, hubungan caregiver dengan lansia). Namun pada penelitian ini yang akan diteliti adalah usia, jenis kelamin, pendidikan, status perkawinan dan status kepegawaian karena berkaitan langsung dengan kondisi Caregiver di panti.

Menurunnya kondisi kesehatan lansia serta tingginya tingkat ketergantungan lansia terhadap Caregiver amat berperan terhadap timbulnya kejadian pengabaian pada lansia (Gorbien \& Eisenstein, 2005 dalam (Amri, 2013). Kejadian pengabaian pada lansia ini menggambarkan bahwa belum optimalnya dukungan keluarga dan masyarakat terhadap perubahan biologis, psikologis dan sosial yang dialami oleh lansia.Perubahan biologis, psikologis dan sosial yang dialami lansia akan menimbulkan berbagai keterbatasan dan meningkatnya ketergantungan lansia terhadap keluarga (caregiver). 
Selain mengalami pengabaian dilingkungan keluarga (rumah), lansia juga beresiko untuk mengalami pengabaian di lembagalembaga seperti : rumah sakit, panti sosial dan lainnya yang memberikan pelayanan dalam jangka panjang. Namun hal ini tidak dalam skala besar (Winterstein, 2012).

PSTW adalah merupakan panti sosial yang mempunyai tugas memberikan bimbingan dan pelayanan bagi lanjut usia terlantar agar dapat hidup secara wajar dalam kehidupan bermasyarakat (KepMenSos No. 50/HUK/2004 dalam situs Kementerian Sosial Republik Indonesia, 2013). Panti sosial memiliki tujuan untuk membantu lansia mengatasi kelemahannya serta hidup secara normal seperti keadaan sebelum mereka masuk panti sosial.

Lansia ada yang secara rela dan sukarela bersedia tinggal di PSTW, dan sebagian lansia lainnya terpaksa menjalani hidupnya di PSTW setelah tidak lagi diperdulikan dan diabaikan oleh keluarganya sendiri. Penelitian yang dilakukan oleh (Komnas Lanjut Usia \& Kementerian Negara Pemberdayaan Perempuan dan Perlindungan Anak, 2009) menyatakan bahwa 50\% lansia yang tinggal di PSTW tidak pernah dikunjungi keluarga, dilupakan oleh keluarganya ataupun tidak diakui sebagai keluarga / orang tua mereka. Kasus lansia yang tidak pernah dikunjungi keluarga, dilupakan oleh keluarganya ataupun tidak diakui sebagai keluarga/orang tua oleh anak ataupun keluarganya yang lain, menjadikan lansia tersebut bergantung sepenuhnya pada petugas panti.

Petugas panti berfungsi sebagai Caregiver bagi lansia di PSTW. Sebagai Caregiver petugas panti beresiko untuk melakukan tindakan pengabaian pada lansia, seperti yang dijabarkan oleh (Robinson, L., Benedictis, T. D., Segal, 2012), yaitu petugas panti sosial beresiko melakukan tindakan pengabaian jika mereka tidak memiliki pengetahuan, pelatihan, memiliki tanggung jawab yang terlalu banyak, yang tidak cocok untuk mengasuh, serta bekerja dibawah kondisi yang buruk.
Public Health Agency of Canada (1994 dalam (Amri, 2013)), menjelaskan bahwa dari hasil studi ditemukan $20 \%$ dari Caregiver mengakui melakukan kelalaian dalam melayani lansia. Studi yang dilakukan oleh Belanger ( Public Health Agency of Canada, 1994 dalam (Amri, 2013)) menyatakan bahwa pengabaian yang dilakukan oleh Caregiver adalah sebesar 25\%. Sementara menurut studi Ontario Collage of Nursing dalam Public Health Agency of Canada, (1994 dalam (Amri, 2013)), menyatakan bahwa kejadian pengabaian yang dilaporkan terjadi di panti sosial adalah sebesar 29\%. Berdasarkan kondisi diatas dan untuk menghindari kejadian pengabaian pada lansia di PSTW ini, maka petugas panti harus memiliki pengetahuan yang baik agar petugas panti bisa lebih optimal dalam bekerja dan pengabaian pada lansia tidak terjadi.

Pengetahuan merupakan domain yang sangat berpengaruh dalam terbentuknya perilaku seseorang, dimana perilaku adalah merupakan keseluruhan (totalitas) pemahaman dan aktivitas seseorang yang merupakan hasil bersama antara faktor internal dan eksternal. Notoatmodjo, (2007dalam (Amri, 2015)), menyatakan bahwa perilaku yang didasari oleh pengetahuan, kesadaran serta sikap yang positif akan membuat perilaku tersebut bersifat langgeng (long lasting). Sementara perilaku yang tidak didasari oleh pengetahuan dan kesadaran maka pengetahuan ini tidak akan berlangsung lama. Oleh karena itu pengetahuan tentang apa itu pengabaian pada lansia ini sangat diperlukan oleh staf (Caregiver), keluarga ataupun masyarakat sehingga dapat mencegah terjadinya pengabaian pada lansia dimanapun lansia itu berada.

Hasil penelitian Amri (2013), menyatakan bahwa kejadian pengabaian pada lansia di PSTW X Sumatera Barat lebih dari separuhnya terjadi kejadian pengabaian tinggi yaitu 57,3 \%. Dari hasil analisis bivariat tentang hubungan antara sikap terhadap apa yang dikerjakan dengan kejadian pengabaian diperoleh bahwa ada sebanyak $64,1 \%$ petugas yang memiliki 
sikap baik melakukan pengabaian rendah pada lansia.

Hasil pengamatan peneliti dilapangan (PSTW yang sama dengan lokasi penelitian Amri, 2013) yang juga merupakan tempat praktek keperawatan Gerontik mahasiswa Poltekkes Kemenkes Padang, memiliki 14 wisma dengan jumlah total kapasitas lansia sebanyak 110 orang. Jumlah Caregiver seluruhnya sebanyak 24 orang dimana jumlah petugas sebanyak 10 orang serta jumlah pengasuh sebanyak 14 orang dengan jumlah pengasuh laki - laki sebanyak 4 orang dan selebihnya adalah perempuan. Umumnya pengasuh ini tinggal langsung didalam wisma.Di PSTW ini terdapat 2 wisma perawatan (laki-laki dan perempuan) dengan jumlah lansia sebanyak 17 orang dan pengasuh untuk kedua wisma ini adalah perempuan.Pengalaman peneliti sewaktu membimbing mahasiswa praktek, ditemukan keluarga dari pengasuh yang melakukan kekerasan secara psikologis terhadap lansia dengan mengeluarkan katakata kasar dan membentak lansia. Informasi yang didapatkan dari salah seorang pengasuh, dari tahun 2013 belum ada satupun Caregiver (pengasuh dan staf) yang mendapatkan pelatihan atau peningkatan ilmu khususnya tentang kesejahteraan lanjut usia.

Tujuan penelitian ini adalah untuk mengetahui efektifitas edukasi pada Caregiver (pengasuh dan staf) tentang pengetahuan kejadian pengabaian lansia di PSTW X Sumatera Barat.

\section{METODE PENELITIAN}

Penelitian ini adalah penelitian kuantitatif yaitu kuasi eksperimen dengan rancangan one group pretest posttest. Metode pengambilan sampel pada penelitian ini adalah dengan cara total sampling. Alat pengumpulan data dalam penelitian ini menggunakan instrumen berupa kuesioner yang kembangkan sendiri oleh peneliti berdasarkan kajian literatur.

Prosedur pengumpulan data dilakukan melalui prosedur administrasi. Pengolahan data dilakukan dengan cara editing, coding, processing, dan cleaning. Analisa data menggunakan analisis univariat dan bivariat.

\section{HASIL DAN PEMBAHASAN}

Tabel. 1 Distribusi usia, jenis kelamin, pendidikan terakhir, status perkawinan,status pegawai petugas PSTW X Sumatera Barat $(n=23)$

\begin{tabular}{|c|c|c|}
\hline Karakteristik & $\begin{array}{c}\text { Jumlah } \\
\text { (n) }\end{array}$ & $\begin{array}{c}\text { Prosentase } \\
(\%)\end{array}$ \\
\hline \multicolumn{3}{|l|}{ Usia } \\
\hline $\begin{array}{l}\text { Remaja Akhir } \\
\text { (17-25 tahun) }\end{array}$ & 2 & 8,7 \\
\hline $\begin{array}{l}\text { Dewasa Awal } \\
(26-35 \text { tahun })\end{array}$ & 7 & 30,4 \\
\hline $\begin{array}{l}\text { Dewasa Akhir } \\
\text { (36- } 45 \text { tahun) }\end{array}$ & 3 & 13,0 \\
\hline $\begin{array}{l}\text { Lansia Awal } \\
\text { (46-55 tahun) }\end{array}$ & 8 & 34,8 \\
\hline $\begin{array}{l}\text { Lansia Akhir } \\
\text { (56-65 tahun) }\end{array}$ & 3 & 13,0 \\
\hline \multicolumn{3}{|l|}{ Jenis kelamin } \\
\hline Laki-laki & 13 & 56,5 \\
\hline Perempuan & 10 & 43,5 \\
\hline \multicolumn{3}{|l|}{ Pendidikan } \\
\hline \multicolumn{3}{|l|}{ Terakhir } \\
\hline SD & 2 & 8,7 \\
\hline SMP & 2 & 8,7 \\
\hline SMA & 7 & 30,4 \\
\hline D III & 2 & 8,7 \\
\hline NERS & 1 & 4,3 \\
\hline PT & 9 & 39,1 \\
\hline \multicolumn{3}{|l|}{ Status } \\
\hline Perkawinan & 22 & 95,7 \\
\hline Kawin & 1 & 4,3 \\
\hline Tidak Kawin & & \\
\hline \multicolumn{3}{|l|}{ Status Pegawai } \\
\hline PNS & 14 & 60,9 \\
\hline Kontrak & 9 & 39,1 \\
\hline Total & 23 & 100 \\
\hline
\end{tabular}

Berdasarkan tabel 1 Petugas terbanyak berada diusia lansia awal yaitu 8 orang $(34,8 \%)$, jenis kelamin petugas yang terbanyak yaitu laki-laki sebanyak 13 orang (56,5\%), pendidikan petugas masih ada yang tamat SD yaitu sebanyak 2 orang $(8,7 \%)$, status perkawinan dari petugas yang terbanyak yaitu kawin sebanyak 22 orang (95,7\%), serta status pegawai masih ada yang Non PNS (kontrak) yaitu 9 orang $(39,1 \%)$.

Hasil analisis peneliti, usiaCaregiver yang bervariasi mulai dari remaja akhir hingga 
lansia akhir ini adalah dikarenakan usia tersebut merupakan usia yang produktif. Sehingga pada rentang usia ini individu mulai memasuki dunia kerja dan akan segera meninggalkan dunia kerja (pensiun). Hasil analisis peneliti ini didukung oleh hasil penelitian (Abdel Rahman \& El Gaafary, 2012) yang menyatakan bahwa usia Caregiver berada antara rentang $<30$ tahun hingga $\geq 50$ tahun, namun demikian dalam penelitian mereka ini tidak dijelaskan berapa batasan tegas usia minimal serta usia maksimal Caregiver. Analisis peneliti tentang usia Caregiver terbanyak berada pada tahap usia lansia awal (usia 45 hingga 66 tahun) yaitu 8 orang $(34,8 \%)$, adalah karena dari awal berdirinya PSTW hingga tahun saat ini hanya beberapa kali terjadi penambahan jumlah Caregiver yang berstatus tetap (PNS).

Hasil penelitian menemukan bahwa jenis kelamin Caregiver terbanyak adalah lakilaki yaitu sebanyak 13 orang (56,5\%). Hasil ini berbeda dengan hasil penelitian yang dilakukan oleh Rahman dan Gaafary (2011), yang menyatakan bahwa dari 1.106 responden, berjenis kelamin perempuan sebanyak 581 orang. Begitu juga dengan penelitian yang dilakukan oleh (Abdel Rahman \& El Gaafary, 2012), yang menyatakan bahwa keseluruhan respondennya adalah perempuan.

Analisis peneliti tentang perbedaan jenis kelamin yang menjadi Caregiver ini adalah berkaitan dengan perbedaan budaya antar daerah bahkan negara.Dimana budaya tidak tertulis di Indonesia, khususnya Sumatera Barat menyatakan bahwa yang harus mencari nafkah adalah laki-laki atau kepala keluarga.Oleh karena itu jenis kelamin Caregiver terbanyak adalah laki-laki.Analis peneliti ini didukung oleh pendapat (Tamimy, 2016), yang menyatakan bahwa salah satu peran dan fungsi seorang ayah adalah mencari nafkah.

Peneliti mendapatkan bahwa pendidikan terakhir Caregiver yang terendah adalah tamat SD yaitu sebanyak 2 orang $(8,7 \%)$ dan yang berprofesi sebagai perawat hanya 1 orang serta sisanya dengan latar belakang pendidikan umum. Hasil penelitian ini tidak jauh berbeda dengan penelitian yang dilakukan oleh (Abdel Rahman \& El Gaafary, 2012), dimana mereka menyatakan bahwa dari 1.106 responden yang buta huruf mencapai 343 responden. Begitu juga dengan hasil penelitian (Daly, J \& Coffey, A, 2010), dimana ia menyatakan bahwa mayoritas responden hanya bersertifikat umum.

Analisis peneliti tentang masih adanya Caregiver yang berpendidikan SD adalah karena dari awal berdirinya PSTW, Caregiver tersebut tidak melanjutkan pendidikan kejejang yang lebih tinggi. Analisis peneliti ini didukung oleh peryataan Caregiver lainnya, dimana Caregiver ini menyatakan bahwa individu tersebut tidak memiliki motivasi untuk melanjutkan pendidikan dan di samping itu dari dinas terkaitpun belum ada dilaksanakannya program Pengembangan Sumber daya Manusia. Kalaupun ada Caregiver yang melanjutkan pendidikan ke jenjang yang lebih tinggi, semua itu semata - mata karena keinginan sendiri serta menggunakan biaya pribadi (Shuci, 2018). Analisis peneliti tentang Caregiver yang berpendidikan Ners (Perawat) hanya satu orang adalah karena masih kurang pahamnya dinas terkait akan pentingnya tenaga perawat dalam memberikan pelayanan kepada lansia terutama lansia dengan kebutuhan khusus. Analisis peneliti ini didukung oleh data bahwa penerimaan pegawai tetap (PNS) terakhir adalah tahun 2015 dengan keilmuan yang tidak spesifik / semua Jurusan(Shuci, 2018).

Hasil penelitian menemukan bahwa status perkawinan Caregiver hampir semuanya adalah menikah yaitu 22 orang (95,7\%). Bertolak belakang dengan penelitian yang dilakukan oleh (Abdel Rahman \& El Gaafary, 2012), dimana mereka menyatakan bahwa dari 1.106 responden, mayoritas berstatus tidak menikah yaitu sebanyak 1.001 responden.

Analisis peneliti terhadap perbedaan status perkawinan ini adalah karena adanya perbedaan budaya dari setiap Negara.Untuk Negara Indonesia sendiri memakai tipe keluarga tradisional, dimana dalam tipe 
tradisional ini suatu keluarga terbentuk oleh sebuah pernikahan / perkawinan. Sementara untuk Negara - Negara yang berbudaya barat, memiliki tipe keluarga non tradisional yang salah satu nya adalah bisa memiliki keluarga tanpa harus memiliki ikatan perkawinan. Analisis peneliti ini didukung oleh pendapat (Friedman.M, Bowden.V.R, Jones, E, 2010) yang menyatakan bahwa tipe - tipe keluarga terdiri dari keluarga tradisional dan keluarga non tradisional.

Hasil penelitian menemukan bahwa status pegawai Caregiver masih ada yang berstatus kontrak yaitu sebanyak 9 orang $(39,1 \%)$. Analisis peneliti menyatakan bahwa masih adanya pegawai dengan status kontrak ini dikarenakan tidak adanya formasi penerimaan pegawai tetap oleh dinas terkait dalam beberapa tahun terakhir ini. Kalaupun ada penambahan, status dari Caregiver tersebut adalah kontrak. Analisis peneliti ini didukung oleh pernyataan dari salah seorang petugas bahwa terakhir penerimaan pegawai tetap (PNS) adalah tahun 2015 dan itu pun dengan keilmuan yang tidak spesifik / semua Jurusan (Shuci, 2018)).

Tabel. 2 Distribusi Tingkat Pengetahuan (Pre dan Post Test) Petugas tentang pengabaian lansia di PSTW X Sumatera Barat $(\mathbf{n}=23)$

\begin{tabular}{lcc}
\hline \multicolumn{1}{c}{ Kategori } & $\begin{array}{c}\text { Jumlah } \\
(\mathbf{n})\end{array}$ & $\begin{array}{c}\text { Prosentase } \\
(\boldsymbol{\%})\end{array}$ \\
\hline Pre Test & 1 & 4,3 \\
Pengetahuan Kurang & 1 & 8,7 \\
Pengetahuan Cukup & 2 & 87,0 \\
Pengetahuan Baik & 20 & \\
\hline Post Test & & 0 \\
Pengetahuan Kurang & 0 & 21,7 \\
Pengetahuan Cukup & 5 & 78,3 \\
Pengetahuan Baik & 18 & 100 \\
\hline \multicolumn{1}{c}{ Total } & 23 & \\
\hline
\end{tabular}

Berdasarkan tabel 2 Tingkat pengetahuan petugas sebelum edukasi diberikan terbanyak berada pada kategori baik yaitu sejumlah 20 orang $(87,0 \%)$, Tingkat pengetahuan petugas sesudah edukasi diberikan terbanyak berada pada kategori baik yaitu sebanyak 18 orang $(78,3 \%)$.

Hasil penelitian didapatkan tingkat pengetahuan petugas sebelum edukasi diberikan tentang kejadian pengabaian pada lansia terbanyak berada pada kategori baik yaitu sebanyak 20 orang $(87,0 \%)$, kategori cukup sebanyak 2 orang $(8,7 \%)$ dan kategori kurang sebanyak 1 orang $(4,3 \%)$. Sementara tingkat pengetahuan petugas sesudah edukasi diberikan tentang kejadian pengabaian pada lansia terbanyak berada pada kategori baik yaitu sebanyak 18 orang $(78,3 \%)$, kategori cukup sebanyak 5 orang $(21,7 \%)$. Karakteristik tingkat pengetahuan antara sebelum diberikan edukasi dengan sesudah diberikan edukasi terdapat perbedaan yang mencolok.Dimana sebelum edukasi diberikan, kategori pengetahuan cukup hanya 2 orang dan sesudah edukasi diberikan, kategori pengetahuan cukup meningkat menjadi 5 orang. Sementara untuk tingkat pengetahuan dengan kategori baik, sebelum edukasi sebanyak 20 orang $(87,0 \%)$ dan sesudah edukasi menurun menjadi 18 orang $(78,3 \%)$.

Analisis peneliti menyatakan, terjadinya peningkatan kategori cukup dan penurunan kategori baik ini adalah karena masih kurangnya pemahaman dan pengetahuan caregiver tentang apa itu sesungguhnya pengabaian lansia, serta kurang antusiasnya caregiver dalam mengikuti kegiatan yang dilakukan oleh peneliti. Analisis peneliti ini didukung oleh pendapat (Janetta Ananias, 2014), yang menyatakan bahwa keengganan caregiver dalam merawat orang tua salah satunya adalah keadaan sosio ekonomi yang memaksa untuk bekerja menjadi caregiver walaupun hal itu bertentangan dengan keinginan mereka. Robinson, L., Benedictis, T. D., Segal, (2012) menjelaskan bahwa petugas panti sosial beresiko melakukan tindakan pengabaian jika mereka tidak memiliki pengetahuan, pelatihan, memiliki tanggung jawab yang terlalu banyak, yang tidak cocok untuk mengasuh, serta bekerja dibawah kondisi yang buruk. Oleh karenanya untuk mencegah terjadinya pengabaian pada lansia ini, sangat diperlukan adanya peningkatan pengetahuan dari Caregiver itu sendiri baik melalui pendidikan formal dan non formal serta pelatihan-pelatihan.

Analisis peneliti ini sejalan dengan pendapat Richardson et al (2002); Sturdy and heath 
(2007); Buzgová and Ivanová (2009); Shinan-Altman and Cohen (2009); Wang et al (2009); (dalam (Daly, J \& Coffey, A, 2010)), yang menyatakan bahwa pendidikan dan pelatihan yang berfokus pada perlindungan lansia sangat penting dalam pencegahan kejadian perlakuan salah pada lansia. Begitupun halnya dengan (Schiamberg et al., 2011), dimana iamenyebutkan bahwa karakteristik Caregiver yang beresiko melakukan perlakuan salah pada lansia berdasarkan tingkat pendidikan, pelatihan yang didapat, keadaan ekonomi serta kemampuan mengelola stress. Hal senada juga di utarakan oleh (Kamavarapu, Ferriter, Morton, \& Völlm, 2017), yang menyatakan bahwa staf yang kurang berkualitas lebih cenderung melakukan pengabaian.

Tabel. 3. Distribusi Perbedaan Pengetahuan (Pre dan Post Test) Petugas tentang pengabaian pada lansia di PSTW $X$ Sumatera Barat $(n=23)$

\begin{tabular}{|c|c|c|c|c|c|}
\hline Variabel & Mean & SD & Min & Maks & $\begin{array}{c}\mathbf{P} \\
\text { Value }\end{array}$ \\
\hline Pengetahuan & & & & & \multirow{3}{*}{0,310} \\
\hline Pre Test & 17,96 & 3,309 & 7 & 21 & \\
\hline Post Test & 17,35 & 3,113 & 9 & 20 & \\
\hline
\end{tabular}

Berdasarkan tabel 3 Rata-rata pengetahuan petugas sebelum edukasi (Pre Test) diberikan adalah 17,96 \% dengan standar deviasi 3,309\%. Pengukuran setelah dilakukan edukasi (Post Test) diberikan adalah $17,35 \%$ dengan standar deviasi $3,113 \%$. Hasil uji statistik didapatkan nilai P Value sebesar 0,310. Maka dapat disimpulkan tidak ada perbedaan yang signifikan antara pengetahuan petugas sebelum diberikan edukasi dengan pengetahuan petugas sesudah diberikan edukasi.

Analisis bivariate yang dilakukan, didapatkan hasil bahwa tidak ada perbedaan yang signifikan antara pengetahuan petugas sebelum diberikan edukasi dengan pengetahuan petugas sesudah diberikan edukasi dengan nilai P Value sebesar 0,310.

Pengetahuan ini erat kaitannya dengan tingkat pendidikan serta prilaku seseorang. Seseorang dengan pendidikan yang lebih tinggi akan mudah menerima informasi dibandingkan seseorang dengan pendidikan yang lebih rendah. Hal ini didukung oleh pernyataan Notoatmodjo (2007 dalam (Amri, 2015)), yaitu Pengetahuan sangat erat kaitannya dengan pendidikan, seyogyanya dimana seseorang dengan pendidikan tinggi maka akan semakin luas pula pengetahuannya. Akan tetapi seseorang yang berpendikan rendah tidak muntlak berpengetahuan rendah pula. Dan Notoatmodjo (2007 dalam (Amri, 2015)), juga menyatakan bahwa Pengetahuan merupakan domain yang sangat penting untuk terbentuknya tindakan seseorang. Pengetahuan diperlukan sebagai dukungan dalam menumbuhkan rasa percaya diri maupun sikap dan perilaku setiap hari, sehingga dapat dikatakan bahwa pengetahuan merupakan fakta yang mendukung tindakan seseorang.

Analisis peneliti tentang tidak ada perbedaan yang signifikan antara pengetahuan petugas sebelum diberikan edukasi dengan pengetahuan petugas sesudah diberikan edukasi adalah karena jawaban yang diberikan bisa saja tidak sesuai dengan kenyataannya.Dalam hal ini caregiver terkesan menutupi kondisi yang sebenarnya, dimana untuk jawaban pertanyaan penelitian hampir seluruhnya berada pada kategori baik.Sementara pada saat peneliti membimbing mahasiswa praktek, ditemukan Caregiver sendiri yang berbicara kasar serta menyepelekan pendapat lansia.Serta keluarga dari caregiver yang melakukan kekerasan secara psikologis terhadap lansia dengan mengeluarkan kata-kata kasar dan membentak lansia. Dengan kata lain prilaku ini disembunyikan dari pihak luar panti.

Analisis peneliti ini berkaitan dengan pernyataan WHO (2002 dalam (Amri, 2013)), bahwa perlakuan salah (fisik, psikologis, finansial, pengabaian dll) pada lansia tersembunyi dari publik atau dengan kata lain perlakuan salah pada lansia ini merupakan sebuah fenomena gunung es. Analisis peneliti juga didukung oleh penelitian (Amri, 2013), dimana ia menyatakan bahwa Sikap kurang baik petugas panti terhadap apa yang dikerjakan dapat menjadi penyebab kejadian 
pengabaian pada lansia.Hal ini terjadi jika petugas panti hanya mengganggap pekerjaan sebagai suatu rutinitas saja, atau bahkan mungkin petugas merasa terpaksa dalam melakukan pekerjaannya, maka petugas tersebut akan beresiko untuk melakukan pengabaian pada lansia.

Analisis peneliti tentang tidak ada perbedaan yang signifikan antara pengetahuan petugas sebelum diberikan edukasi dengan pengetahuan petugas sesudah diberikan edukasi adalah karena variable dependen (pengetahuan Caregiver) dipengaruhi oleh fariabel perancu (Confounding) yang meliputi 1).Usia. Usia Caregiver yangtidak homogen akan mempengaruhi pengalaman hidup sehingga perlakuan pada lansiapun akan berbeda. Hal ini sesuai dengan pendapat (Janetta Ananias, 2014) yang menyatakan bahwa adanya keengganan serta kurangnya pengalaman pengasuh dalam merawat orang tua merupakan salah satu faktor resiko tindak pengabaian; 2). Jenis kelamin. Jenis kelamin memiliki kemungkinan yang sama dalam melakukan tindak pengabaian pada lansia. Hal ini sesuai dengan hasil penelitian dari (Kohn, Robert \& Oftedahl, 2011) yang menyatakan bahwa pelaku yang beresiko melakukan tindak pengabaian adalah perempuan. Sementara (Kamavarapu et al., 2017) menyatakan bahwa staf laki-laki lebih banyak melakukan tindak perlakuan salah pada lansia.

Selanjutnya variabel perancu yang ke 3).Pendidikan terakhir.Masih adanya pendidikan terakhir Caregiver yang hanya tamat SD, SMP dan SMA serta bukan brstatus perawat sangat mempengaruhi pengetahuan Caregiver tentang tindak pengabaian pada lansia.Hal ini sesuai dengan pendapat (Kohn, Robert \& Oftedahl, 2011), yang menyatakan bahwa status kognitif Caregiver yang kurang merupakan salah satu faktor resiko pelaku tindak pengabaian pada lansia. Begitupun dengan (Schiamberg et al., 2011), yang menjelaskan bahwa tingkat pendidikan Caregiver menjadi salah satu factor resiko terjadinya tindak pengabaian pada lansia; 4). Status Kepegawaian. Dengan masih banyaknya Caregiver yang berstatus kontrak (dengan penghasilan rendah) sementara tugas dan kewajiban tidak jauh berbeda dengan pegawai tetap, akan memicu tindak pengabaian pada lansia. Hal ini senada dengan hasil penelitian Shinan, Altman dan Cohen (2009 dalam(Castle, FergusonRome, \& Teresi, 2015) yang menyatakan bahwa tingginya tingkat stress pekerjaan, kelelahan serta penghasilan yang rendah menjadi salah satu faktor resiko terjadinya tindak pengabaian pada lansia.

Variabel perancu terakhir yaitu yang ke 5).Status Perkawinan.Masalah yang dimiliki dalam sebuah perkawinan, juga dapat memicu terjadinya tindak pengabaian pada lansia.Pernyataan ini sesuai dengan penjelasan dari (Kamavarapu et al., 2017), yaitu situasi kehidupan pribadi yang menengangkan, status perkawinan pengasuh, jumlah anak, serta situasi keluarga yang disfungsional menjadi salah satu faktor tindak perlakuan salah.

Dari penjelasan diatas dapat disimpulkan bahwa masing - masing variabel perancu ini, baik secara langsung ataupun tidak langsung, suka atau tidak suka akan mempengaruhi pengetahuan dari Caregiver itu sendiri tentang tindak pengabaian pada lansia. Dengan demikian untuk mencegah terjadinya pengabaian ini, memang sangat dibutuhkan seseorang dengan pengetahuan yang tepat tentang cara merawat dan berinteraksi dengan lansia. Khususnya perawat professional yang memang memiliki ilmu dan bertugas untuk merawat individu yang memiliki masalah baik itu fisik maupun masalah psikososial.Pengetahuan ini bisa didapat secara formal dan informal, pendidikan berkelanjutan ataupun melalui pelatihan pelatihan yang diadakan oleh institusi pemerintah maupun swasta.

\section{SIMPULAN}

Hasil penelitian menemukan bahwa usia Caregiver bervariasi dan terbanyak berada pada tahap usia lansia awal (usia 45 hingga 66 tahun) yaitu 8 orang $(34,8 \%)$. Jenis kelamin Caregiver terbanyak adalah lakilaki yaitu sebanyak 13 orang (56,5\%). Peneliti mendapatkan bahwa pendidikan 
terakhir Caregiver yang terendah adalah tamat SD yaitu sebanyak 2 orang $(8,7 \%)$ dan yang berprofesi sebagai perawat hanya 1 orang serta sisanya dengan latar belakang pendidikanumum. status perkawinan Caregiver hampir semuanya adalah menikah yaitu 22 orang $(95,7 \%)$. Status pegawai Caregiver masih ada yang berstatus kontrak yaitu sebanyak 9 orang $(39,1 \%)$. Tingkat pengetahuan petugas sebelum edukasi diberikan tentang kejadian pengabaian pada lansia terbanyak berada pada kategori baik yaitu sebanyak 20 orang $(87,0 \%)$. Tidak ada perbedaan yang signifikan antara pengetahuan petugas sebelum diberikan edukasi dengan pengetahuan petugas sesudah diberikan edukasi.Hal ini bisa terjadi karena adanya variabel perancu yang mempengaruhi pengetahuan Caregiver itu sendiri.

\section{UCAPAN TERIMA KASIH}

Terimakasih tak terhingga penulis ucapkan kepada seluruh pihak yang telah membantu terutama pihak PSTW, sehingga penelitian ini dapat diselesaikan dengan baik. Semoga dengan adanya penelitian ini, pejabat yang berwenang dapat menempatkan petugas panti sesuai dengan peran dan fungsi serta kewenangannya, melakukan pelatihan pada seluruh petugas panti werdha mengenai kesejahteraan lansia terutama tentang pemenuhan kebutuhan dasar lansia, memfasilitasi pegawainya untuk melanjutkan pendidikan yang sesuai terutama di bidang kesehatan, agar panti werdha memiliki SDM yang lebih memadai serta memiliki pengetahuan lebih baik lagi sehingga kejadian pengabaian pada lansia bisa di hindari.

\section{DAFTAR PUSTAKA}

Abdel Rahman, T. T., \& El Gaafary, M. M. (2012). Elder mistreatment in a rural area in Egypt. Geriatrics and Gerontology International, 12(3), 532-537.

https://doi.org/10.1111/j.1447-

0594.2011.00780.x

Amri, L. F. (2013). Hubungan Budaya Kerja Petugas Panti Menurut Persepsi Lansia dengan Kejadian Pengabaian di PSTW $\mathrm{X}$ Sumatera Barat. Universitas Indonesia.

Amri, L. F. (2015). Gambaran Kejadian Pengabaian Lansia di Kota Padang. Jurnal Sehat Mandiri, 10(1).

Castle, N., Ferguson-Rome, J. C., \& Teresi, J. A. (2015). Elder abuse in residential long-term care: An update to the 2003 National Research Council report. Journal of Applied Gerontology, 34(4), 407-443. https://doi.org/10.1177/07334648134 92583

Daly, J \& Coffey, A. (2010). Staff Perceptions Of Elder Abuse. Nursing Older People. 22(4).

Friedman.M, Bowden.V.R, Jones, E, G. (2010). Family Nursing,Research, Theory, and Practice (5th edition; dkk Hamid, A.Y.S, Ed.). Jakarta: EGC.

Fulmer. T. Et Al. (2005). Dyadic Vulnerability and Risk Profiling for Elder Neglect: The Gerontologist. ProQuest, 45(4), 525 - 534.

Gorbien, M., J., \& Eisenstein, A. R. (2005). Elder abuse and neglect: An overview. Clinics in Geriatric Medicine, 21(2), 279-292.

https://doi.org/10.1016/j.cger.2004.12 .001

Janetta Ananias, H. S. (2014). FACTORS CONTRIBUTING TO ELDER ABUSE AND NEGLECT IN THE INFORMAL CAREGIVING SETTING Janetta Ananias, Herman Strydom. 50(2), 268-284. Retrieved from http://www.scielo.org.za/scielo.php?s cript=sci_arttext\&pid=S003780542014000300007

Kamavarapu, Y. S., Ferriter, M., Morton, S., \& Völlm, B. (2017). Institutional abuse - Characteristics of victims, perpetrators, and organizations: A systematic review. European Psychiatry, 40, 45-54. https://doi.org/10.1016/j.eurpsy.2016. 07.002

Kementerian Sosial Republik Indonesia. (2013). Glosarium Penyelenggaraan Kesejahteraan Sosial. Retrieved from http://www.kemsos.go.id/modules.ph 
$\mathrm{p}$

Kohn, Robert \& Oftedahl, W. V. (2011). Caregiving and Elder Abuse. HSS Public Access. Med Health R I.

Komnas Lanjut Usia \& Kementerian Negara Pemberdayaan Perempuan dan Perlindungan Anak. (2009). Tindak Penipuan, Pelecehan, Penelantaran dan kekerasan terhadap Lanjut Usia.

Potter.A.P \& Perry.G. A. (2009). Fundamental Keperawatan (7th ed.). Jakarta : Salemba Medika.

Robinson, L., Benedictis, T. D., Segal, J. (2012). Elder Abuse and Neglect: Warning Signs, Risk Factors, Prevention, and Help. Retrieved from http://www.helpguide.org/.

Schiamberg, L. B., Barboza, G. G., Oehmke, J., Zhang, Z., Griffore, R. J., Weatherill, R. P., ... Post, L. A. (2011). Elder abuse in nursing homes: An ecological perspective. Journal of Elder Abuse and Neglect, 23(2), 190211.

https://doi.org/10.1080/08946566.201 1.558798

Shuci. (2018). Personal interview by phone. Stanhope, M \& Lancester, J. (2004). Community \& Public Health Nursing ((six ed)). St.Louis, Missouri: Mosby.

Tamimy, M. F. (2016). 13 Fungsi Ayah di Dalam Keluarga. Http://Www.Psikoma.Com. Retrieved from http://www.psikoma.com/fungsiayah-di-dalam-keluarga/

Winterstein, T. B. (2012). Nurses' Experiences of the Encounter With Elder Neglect. Journal of Nursing Scholarship, 44(1), 55-62. https://doi.org/10.1111/j.1547-

5069.2011.01438.x 